\title{
LÂM SÀNG, CÂN LÂM SÀNG CỦA THAI PHỤ ĐÁI THÁO ĐƯờnG THAI KỲ ĐẺ ĐỬ THÁNG TẠI BỆNH VIỆN PHỤ SẢN TRUNG ƯƠNG
}

\section{TÓM TẮT}

Mục tiêu: Mô tả đặc điểm lâm sàng, cận lâm sàng của thai phụ đái tháo đường thai kỳ đẻ đủ tháng tại Bệnh viện Phụ sản Trung ương năm 2019-2020. Kểt quả: Độ tuổi trung bình của nhóm bênh nhân ĐTĐTK là $32,05 \pm 4,89$ tuổi, tuổi nhỏ nhất là 20 tuổi và độ tuổi lớn nhất là 43 tuổi. Phần lớn bênh nhân được phát hiện ĐTĐTK trong khoảng thời gian từ 24 đến 28 tuần, chiếm tỷ lê $71,76 \%$. Thai phư có thừa cân và béo phì có tỳ lệ mắc ĐTĐTK cao (chiếm 35,53\%). Thai phụ ĐTĐTK có tỷ lệ tăng cân $>12 \mathrm{~kg}$ trong quá trình mang thai chiếm cao với tỷ lệ là $31,17 \%$.Tại thời điểm phát hiên ĐTĐTK có 30,59\% bênh nhân đước xác định đa ối. Kết luận: Thai phụ ĐTĐTK có tuổi trung bình khá cao, thường gặp ở người thừa cân/béo phì và có tỷ lê tăng cân nhanh trong quá trình mang thai (tăng $>12 \mathrm{~kg}$ ) và có tình trạng đa ối ở thời điểm phát hiện.

Tư khoá: đái tháo đường thai kỳ, thừa cân, béo phì, đa ối

\section{SUMMARY \\ CLINICAL FEATURES AND LABORATORY TESTS OF GESTATIONAL DIABETES \\ MELLITUS (GDM) IN NATIONAL HOSPITAL OF OBSTETRICS \& GYNECOLOGY}

Objective: Describe the clinical features and laboratory tests of Gestational diabetes mellitus (GDM) in National Hospital of Obstetrics \& Gynecology between 2019 and 2020. Results: The average age of women with GDM was $32.05 \pm 4.89$, of which the youngest one was 20 years old and the oldest one was 43 years old. The majority of patients $(71.76 \%)$ were diagnosed with GDM during the period from 24 to 28 weeks pregnant. Pregnant women with overweight and obesity were at high risk of GDM, accounted for $35.53 \%$. Women who gained too much weight during pregnancy (> $12 \mathrm{~kg}$ ) were also at high risk of GDM, accounted for $31.17 \%$. At the time of diagnosis of GDM, $30.59 \%$ of patients were identified as polyhydramnios. Conclusions: Women with GDM had a relatively high average age. GDM was common in women with overweight, obesity, excessive weight gain during pregnancy ( $>12 \mathrm{~kg})$, and polyhydramnios at the time of diagnosis of GDM.

Key words: Gestational diabetes mellitus, overweight, obesity, polyhydramnios.

\section{*Trường Đại học Y Hà Nội}

Chịu trách nhiệm chính: Nguyễn Mạnh Thắng

Email: bsnguyenmanhthang@gmail.com

Ngày nhận bài: 4.3.2021

Ngày phản biên khoa học: 26.4.2021

Ngày duyệt bài: 7.5.2021
Nguyễn Mạnh Thắng*

\section{I. ĐĂT VẤN ĐỀ}

Đái tháo đường thai kỳ (ĐTĐTK) là môt thể của bệnh đái tháo đường (ĐTĐ), là bệnh rối loạn chuyển hoá thường gặp nhất trong thai kỳ và có xu hướng ngày càng tăng, nhất là khu vực châu Á - Thái Bình Dương, trong đó có Việt Nam [1]. Theo định nghĩa của Tổ chức $Y$ tế thế giới (WHO), ĐTĐTK "là tình trạng rối loạn dung nạp glucose ở bất kỳ mức độ nào, khởi phát hoặc được phát hiện lần đầu tiển trong lúc mang thai" [1]. Có nhiều bằng chứng chỉ ra mối liên hệ giữa ĐTĐTK với tăng tỷ lệ các biến cố chu sinh ở me và thai nhi như tiền sản giật, sảy thai, thai chết lưu, thai to gây đẻ khó, ngạt sơ sinh. Trẻ sơ sinh của những bà mẹ bị ĐTĐTK có nguy cơ cao bị hạ đường máu, vàng da và nguy cơ bị béo phì, ĐTĐ týp 2 [2]. Khoảng 30-50\% phụ nữ mắc ĐTĐTK sẽ tiếp tục mắc ĐTĐTK trong lần mang thai tiếp theo, và có nguy cơ mắc ĐTÐ týp 2 về sau. So với phụ nữ da trắng, phụ nữ vùng Đông Nam Á có nguy cơ mắc ĐTĐTK cao hơn 7,6 lần [3]. Viêtt Nam là nước nằm trong vùng có nguy cơ mắc ĐTĐTK cao. Tỷ lệ ĐTĐTK ở nước ta dao động từ $3,6-39 \%$, thay đổi tuỳ theo vùng miền. Nghiên cứu được thực hiện với mục tiêu: Mô tả đặc điểm lầm sàng, cần lâm sàng của thai phụ đái tháo đường thai kỳ đẻ đủ tháng tại Bệnh viện Phu sản Trung ương năm 2019-2020.

\section{II. ĐỐI TƯỢNG VÀ PHƯƠNG PHÁP NGHIÊN CỨU}

\section{1. Đối tượng nghiên cứu.}

2.1.1. Tiêu chuẩn lựa chọn

- Được chẩn đoán ĐT̈ĐTK đến điều trị và đẻ đủ tháng tại bệnh viện Phụ sản Trung ương từ tháng 7 - 2019 đến tháng 7 - 2020.

- Đơn thai

- Tuổi thai từ 37 tuần 01 ngày đến 41 tuần 6 ngày.

- Có hồ sơ me và sơ sinh được ghi chép đây đủ rõ ràng về hành chính, chuyên môn, xét nghiệm trước và sau khi đẻ

2.1.2. Tiêu chuẩn loại trừ

- Thai phụ đã được chẩn đoán ĐTĐ trước khi có thai.

- Thai phụ đang mắc các bệnh có ảnh hưởng đến chuyển hóa glucose như Basedow, suy giáp, Cushing, suy gan, suy thận,...

- Các thai phụ không đảm bảo đủ các tiêu chuẩn chọn mấu

2.1.3. Thời gian và địa điểm nghiên cứu 
- Thời gian nghiên cứu: từ tháng 7 - 2019 đến tháng $7-2020$.

- Địa điểm nghiên cứu: Bệnh viện Phụ sản Trung Ương

\subsection{Phương pháp nghiên cứu.}

2.2.1. Thiết kế nghiên cứu: mô tả cắt ngang.

2.2.2. Mẫu nghiên cứu: được thực hiện ở 170 thai phụ, với cách chọn mẫu thuận tiện.

\subsubsection{Các biến số nghiên cứu}

- Đặc điểm đối tượng nghiên cứu:

+ Tuổi mẹ: tính theo năm dương lịch.

+ Trình đố văn hóa, nghề nghiệp của thai phu

+Tuổi thai: Dựa vào ngày đầu của kỳ kinh cuối cùng, nếu không nhớ ngày kinh thì dựa vào kết quả siêu âm 3 tháng đầu để ước tính tuổi thai.

- Đặc điểm lâm sàng, cận lân sàng thai phụ ĐTÐTK:

+ Chỉ số BMI (chiều cao và cân nặng) trước khi mang thai.

+ Tiền sử gia đình thế hệ một (bố, mẹ, anh, chị, em ruột) có người bị ĐTĐ.

+ Tiền sử thai phụ có rối loạn dung nạp glucose trước đó

+ Tiền sử đẻ con to $\geq 4000 \mathrm{~g}$, tiền sử đẻ con dị tật, sẩy thai, thai lưu.

+ Số lần mang thai: tất cả số lần mang thai.

+ Tiền sử đẻ con to $\geq 4000 \mathrm{~g}$.

+ Số kg tăng cân trong thai kỳ

+ Chỉ số ối.

2.3. Quản lý và phân tích số liệu: Tất cả các số liệu đều được ghi lại trong mẫu hồ sơ nghiên cứu và nhập vào máy tính để phân tích và xử lý số liệu. Chúng tôi sử dụng phần mềm thống kê SPSS 26.0 để quản lý, tính toán, xử lý các dữ liệu thống kê.

2.4. Đao đức của nghiên cứu. Đề tài nghiên cứu được thông qua Hội đồng đạo đức của Bệnh viện Phụ sản Trung Ương, được sự chấp thuận của ban giám đốc Bệnh viện.Tất cả các bệnh nhân được mời tham gia nghiên cứu đều được giải thích rõ ràng về mục tiêu nghiên cứu, những lợi ích lâu dài nhờ nghiên cứu này mang lại.Những thông tin có được từ nghiên cứu sẽ được bảo mật và chỉ được sử dụng cho nghiên cứu.

\section{KẾT QUẢ NGHIÊN CỨU}

Kết quả nghiên cứu cho thây, tuổi trung bình của nhóm bệnh nhân ĐTĐTK là 32,05 \pm 4,89, tuổi nhỏ nhất là 20 tuổi và độ tuổi lớn nhất là 43 tuổi. Bệnh nhân ở nhóm tuổi $25-29$ chiếm tỷ lệ lớn nhẩt với 60 bênh nhân (35,3\%). Nhóm $\leq 24$ tuổi chiếm tỷ lệ thấp nhất với $2,4 \%$.Phần lớn bệnh nhân bị ĐTĐTK trong nhóm nghiên cứu sống ở thành thị, chiếm tỷ lệ 75,29\%.

Đa số thai phụ mắc ĐTĐTK là các thai phụ đẻ con dạ (chiếm 72,94\%), tỷ lệ ĐTĐTK ở thai phụ đẻ con so là $27,06 \%$.

Bảng 1. Đăc điểm BMI của bênh nhân trước mang thai

\begin{tabular}{|c|c|c|}
\hline Phân loại BMI & $\mathbf{n}$ & $\mathbf{\%}$ \\
\hline Thiếu cân & 28 & $16,47 \%$ \\
\hline Bình thường & 85 & $50,00 \%$ \\
\hline Thữa cân & 33 & $19,41 \%$ \\
\hline Béo phì độ 1 & 18 & $10,59 \%$ \\
\hline Béo phì độ 2 & 6 & $3,53 \%$ \\
\hline BMI trung bình & \multicolumn{2}{|c|}{$22,24 \pm 2,7$} \\
\hline Tổng & $\mathbf{1 7 0}$ & $\mathbf{1 0 0} \%$ \\
\hline
\end{tabular}

Nhận xét: Trong số 170 bệnh nhân, số lượng bệnh nhân có chỉ số BMI trong mức bình thường chiếm tỷ lệ cao nhất với 85 người, chiếm $50 \%$. Có 6 bênh nhân thuộc nhóm béo phì độ 2 bị đái tháo đường thai kỳ, chiếm 3,53\%. Tổng số bệnh nhân từ nhóm thừa cân trở lên bị ĐTĐTK là 57 bệnh nhân, chiếm tỷ lệ 35,53\%.

Phần lớn bệnh nhân ĐTĐTKtăng cân từ $8-12$ $\mathrm{kg}$ trong suốt quá trình mang thai, chiếm tỷ lê 48,24\%. Có 53 bệnh nhân tăng cần từ $12 \mathrm{~kg}$ trở lên, chiếm tỷ lệ $31,17 \%$. Số cân nặng tăng nhiều nhất là $18 \mathrm{~kg}$, đây cũng là bệnh nhân có tình trạng đa ối khi chuẩn bị sinh, và cân nặng lúc sinh của bệnh nhân là $80 \mathrm{~kg}$.

Bảng 3. Thời điểm phát hiện ĐTĐTK

\begin{tabular}{|c|c|c|}
\hline Tuần thai & $\mathbf{n}$ & $\mathbf{\%}$ \\
\hline Trước tuần 24 & 19 & $11,18 \%$ \\
\hline Từ 24-28 tuần & 122 & $71,76 \%$ \\
\hline Sau tuần 28 & 29 & $17,06 \%$ \\
\hline Thời điểm trung bình & $25,63 \pm 3,37$ \\
\hline Thời điểm sớm nhất & \multicolumn{2}{|c|}{12} \\
\hline Thời điểm muộn nhất & \multicolumn{2}{|c|}{32} \\
\hline Tổng & $\mathbf{1 7 0}$ & $\mathbf{1 0 0} \%$ \\
\hline
\end{tabular}

Nhận xét: Thời điểm trung bình phát hiên ĐTĐTK là 25,63 $\pm 3,37$ tuần. Phần lớn bênh nhẩn được phát hiện ĐTĐTK trong khoảng thời gian từ 24 đến 28 tuần, chiếm tỷ lệ $71,76 \%$.

Có 19 bệnh nhân được phát hiện ĐTĐTK trước tuần 24 , phần lớn bệnh nhân trong nhóm này có tiền sử ĐTĐTK ở lần mang thai trước hoặc có nhiều yếu tố nguy cơ. Thời điểm phát hiện sớm nhất là 12 tuần.

Có 29 bệnh nhân được phát hiện ĐTĐTK muộn sau 28 tuần, những bệnh nhân này chủ yếu không đi sàng lọc trong mốc 24 - 28 tuần, thời điểm phát hiện muộn nhất là 32 tuần.

Bảng 4. Yếu tố nguy cơ bênh nhân ĐTĐTK

Yếu tố nguy cơ

\begin{tabular}{l|l}
$\begin{array}{l}\text { Số bệnh } \\
\text { nhân có }\end{array}$ & $\begin{array}{c}\text { Tỷ lệ } \\
\%\end{array}$ \\
\hline
\end{tabular}




\begin{tabular}{|c|c|c|}
\hline & $\begin{array}{c}\text { yếu tố } \\
\text { nguy cơ }\end{array}$ & \\
\hline $\begin{array}{c}\text { Tiền sử gia đình ĐTĐ thế } \\
\text { hê̂ thứ nhất }\end{array}$ & 25 & $14,71 \%$ \\
\hline Tiền sư đẻ con $\geq 4000 \mathrm{gr}$ & 15 & $8,23 \%$ \\
\hline $\begin{array}{c}\text { Tiền sử ĐTĐ lần mang } \\
\text { thai trước }\end{array}$ & 32 & 18,82 \\
\hline $\begin{array}{c}\text { Tiền sử rối loạn dung } \\
\text { nạp Glucose }\end{array}$ & 18 & $10,59 \%$ \\
\hline $\begin{array}{c}\text { Tiền sữ thai lưu không rõ } \\
\text { nguyên nhân }\end{array}$ & 64 & $37,67 \%$ \\
\hline Tiền sử sấy thai liên tiếp & 17 & $10,0 \%$ \\
\hline $\begin{array}{c}\text { Hội chứng buồng trứng } \\
\text { đa nang }\end{array}$ & 22 & $12,94 \%$ \\
\hline Glucose niệu (+) & 35 & $20,59 \%$ \\
\hline Thừa cân, béo phì & 57 & $33,53 \%$ \\
\hline
\end{tabular}

Nhận xét: Trong số 9 yếu tố nguy cơ kể trên, yếu tố tiền sử thai lưu không rõ nguyên nhân chiếm tỷ lệ nhiều nhất với 64/170 bệnh nhân mắc phải, chiếm tỷ lệ $37,67 \%$.Yếu tố nguy cơ có: tiền sử đẻ con $\geq 4000 \mathrm{gr}$ có tỷ lệ ít nhất với chỉ 15 trường hợp, chiếm tỳ lệ 8,23\%.

Bảng 5. Tinh trạng ối tại thời điểm phát hiện ĐTÐTK của bệnh nhân

\begin{tabular}{|c|c|c|}
\hline Tình trạng ối & $\mathbf{n}$ & $\mathbf{\%}$ \\
\hline Öi bình thường & 118 & $69,41 \%$ \\
\hline Đa ối & 52 & $30,59 \%$ \\
\hline Tổng & $\mathbf{1 7 0}$ & $\mathbf{1 0 0 \%}$ \\
\hline
\end{tabular}

Nhận xét: Phần lớn bệnh nhân có chỉ số ối bình thường, chiếm tỷ lệ 69,41\%. Có 52 bệnh nhân được xác định đa ối tại thời điểm phát hiện ĐTĐTK chiếm tỷ lệ 30,59\%.

Bảng 6. Tình trạng ối tại thời điểm trước sinh (trước vỡ ôi đôî́ với những bệnh nhân vào viện vì ối vớ)

\begin{tabular}{|c|c|c|}
\hline Tình trang ối & $\mathbf{n}$ & $\mathbf{\%}$ \\
\hline Thiếu ối & 15 & $8,82 \%$ \\
\hline Öi bình thường & 133 & $78,24 \%$ \\
\hline Đa ối & 22 & $12,94 \%$ \\
\hline Tống & $\mathbf{1 7 0}$ & $\mathbf{1 0 0 \%}$ \\
\hline
\end{tabular}

Nhân xét: Tại thời điểm trước sinh, bênh nhân có chỉ số ối bình thường có tỷ lệ cao nhất với 133 bệnh nhân, chiếm 78,24\%.Bệnh nhân được xác định đa ối giảm từ 52 bệnh nhân tại thời điểm phát hiện ĐTĐTK xuống chỉ còn 22 bệnh nhân tại thời điểm trước sinh. Có 15 bênh nhân ĐTĐTK có chỉ số ối ở mức thiểu ối, chiếm tỷ lệ thấp nhất với chỉ 8,82\%.

\section{BÀN LUÂN}

Trong số 170 bệnh nhân ĐTĐTK đẻ đủ tháng trong nhóm nghiên cứu của chúng tôi, độ tuổi trung bình là 32,05 $\pm 4,89$, tuổi nhỏ nhất là 20 tuổi và độ tuổi lớn nhất là 43 tuổi. Nhóm tuổi từ
25 - 29 chiếm tỷ lệ lớn nhất với 60 bệnh nhân, chiếm 35,3\%.Phân bố tuổi trong nghiên cứu của chúng tôi cũng tương đồng so với kết quả nghiên cứu của tác giả Lương Thanh Hương (2018), khi nhóm có độ tuổi từ 25- 29 tuổi chiếm tỷ lệ cao nhất với 38,7\% [4]. Độ tuổi trung bình trong nghiên cứu của chúng tôi cũng tương đồng với tác giả Phan Thị Thu Hằng (2016) khi cho thấy độ tuổi trung bình trong nhóm thai phụ ĐTĐTK là 32,46 $\pm 5,49$, tuổi thấp nhất là 19 và cao nhất là 45 tuổi.Tỷ lệ mắc ĐTĐTK tăng dần theo tuổi, thai phụ càng lớn tuổi thì tỷ lệ mắc ĐTĐTK càng cao..

Trong nghiên cứu của chúng tôi, tỷ lệ bệnh nhân ĐTĐTK mang con thứ 2 chiếm tỷ lệ cao nhất với $52,35 \%$; Tỷ lệ con so chiếm ít nhất với 27,06\%. Nghiên cứu của tác giả Lê Thị Thanh Tâm và cộng sự (2016) nhận thấy so với nhóm con so, nguy cớ mắc ĐTÐTK của thai phụ tăng 1,5 lần ở nhóm mang thai lần thứ 2 và tăng 2,2 lần ở nhóm mang thai lần thứ 3 trở lên [5]. Tác giả Lê Thanh Tùng (2010) cũng thấy rằng tỷ lệ ĐTĐTK ở các thai phụ mang thai con dạ cao hơn so với các thai phụ mang thai con so. Các tác giả này đều nhận định mang thai con dạ cũng là một yếu tố nguy cơ đối với ĐTĐTK. Các thai phụ mang thai con dạ có tuổi mẹ cao hơn các thai phụ mang thai con so. Do đó nguy cơ mắc ĐTĐTK cũng tăng lên.

Trong số 170 bệnh nhân, số lượng bệnh nhân có chỉ số BMI trong mức bình thường chiếm tỷ lệ cao nhất với 85 người, chiếm $50 \%$, có 6 bênh nhân thuộc nhóm béo phì độ 2 bị đái tháo đường thai kỳ, chiếm 3,53\%. Tổng số bệnh nhân từ nhóm thừa cân trở lên bi ĐTĐTK là 57 bênh nhân, chiếm tỷ lệ 35,53\%. Và chỉ số BMI trung bình của bệnh nhân ĐTĐTK trong nghiên cứu của chúng tôi là $22,24 \pm 2,7$. Kết quả của chúng tôi tương tự theo nghiên cứu của tác giả J.Martino và cộng sự tại Tây Ban Nha nhận thấy BMI trung bình trước khi mang thai ở nhóm thai

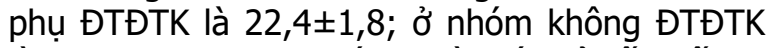
là $21,8 \pm 1,8$ [6].So với người có chỉ số khối cơ thể bình thường thì nguy cơ mắc ĐTĐTK giảm ở người gầy $(O R=0,6)$, tăng ở người thừa cân $(\mathrm{OR}=4,5)$ và béo phì $(\mathrm{OR}=11,2)$. Nếu gộp chung người thừa cân, béo phì thì nguy cơ mắc ĐTĐTK tăng 6,1 lần $(4,1-9,0)$ so với người bình thường. Qua phân tích hồi quy đa biến cũng cho thấy chỉ số BMI trước khi mang thai của mẹ $\geq 23$ có liên quan với bệnh ĐTĐTK [7].Nhiều nghiên cứu cũng đã cho thấy chỉ số BMI trước khi mang thai có ảnh hưởng đến ĐTĐTK. Theo Torloni, so với nhóm có $B M I$ bình thường thì nguy cơ mắc 
ĐTĐTK của nhóm có cân năng thấp giảm ( $O R=$ $0.75,95 \% \mathrm{CI}=0.69-0.82)$, của nhóm thừa cân, béo phì vừa phải và béo phì tăng tương ứng 1.97 lần, 3.01 lần và 5.55 lần [7]. Nguy cơ mắc ĐTĐTK liên quan dương tính với chỉ số BMI trước khi mang thai, thông tin này rất quan trọng khi tư vấn cho những phụ nữ đang có kê hoạch mang thai.

Khuyên cáo của ACOG năm 2013, mức tăng cân đến hết quý 2 của các thai phụ với BMI trước khi mang thai thai bình thường là $6 \mathrm{~kg}$. Tăng cân quá nhiều trong thời gian mang thai sẽ dẫn đến tăng lắng đọng chất béo trong cơ thể người me đe điêu này có thể làm giảm độ nhạy insulin, dấn đến gia tăng ĐTĐTK. Nghiên cứu của tác giả Stefanie Brunner và cộng sự cho thây tăng cân quá mức trong thai kỳ là YTNC của ĐTĐTK (OR=1,42; 95\% CI 1,20 - 1,68) [8].Kết quả nghiên cứu cho thấy, phần lớn bệnh nhân tăng cân từ $8-12 \mathrm{~kg}$ trong suốt quá trình mang thai, chiếm tỷ lệ 48,24\%. Có 53 bệnh nhân tăng cần từ $12 \mathrm{~kg}$ trở lên, chiếm tỷ lệ $31,17 \%$. Số cân nặng tăng nhiều nhất là $18 \mathrm{~kg}$, đây cũng là bệnh nhân có tình trạng đa ối khi chuẩn bị sinh. Và cân nặng lúc sinh của bệnh nhân là $80 \mathrm{~kg}$.Đối với những thai phụ có BMI trước khi mang thai ở mức bình thường nếu trọng lượng tăng đến hết quý 2 từ $7 \mathrm{~kg}$ trở lên sẽ có nguy cơ mắc ĐTĐTK cao hơn nhóm còn lại 3,1 lần $(p=0,000)$. Nghiên cứu của tác giả Stefanie Brunner và cộng sự trên 13748 thai phụ trong thời gian từ 1990 - 2014 cũng cho thấy kết quả tương đồng [8]. Có thể coi tăng cân quá mức trong thời gian mang thai là yếu tố nguy cơ có thể sửa đổi của ĐTĐTK. Qua đó khẳng định vai trò quan trọng của việc xác định BMI trước khi mang thai ngay trong lần khám thai đầu tiên và theo dõi cân nặng của thai phụ trong suốt thai kỳ. Dựa vào đó nhân viên y tế có thế xác định các thai kỳ có nguy cơ cao và đưa ra lời khuyên về chế đô dinh dưỡng hợp lý. Giảm tỷ lệ tăng cân quá mức là biện pháp không khó để thực hiện giúp giảm tỷ lệ ĐTĐTK cũng như các biến cố bất lợi khác cho cá me và thai.

Kết quả nghiên cứu của chúng tôi cho thấy: tại thời điểm phát hiên ĐTĐTK, có 52 bênh nhân qua siêu âm phát hiện đa ối, tỷ lệ ối trung bình chiếm cao nhất với 118 trường hợp. Sau đó tại thởi điểm trước sinh, chỉ còn 22 trường hợp bệnh nhân siêu âm còn phát hiện đa ối chiểm $12,94 \%$, tỷ lệ ối trung bình tăng lên thành $78,24 \%$. Nghiên cứu của chúng tôi cũng cho nhận định như của tác giả Vũ Thanh Vân (2012), khi tác giả chỉ ra răng tỷ lê đa ối của nhóm bênh nhân ĐTĐTK giảm từ 20,67\% tại thời điểm phát hiện xuống còn 9,52\% tại thời điểm trước sinh [9].Nguyên nhân của đa ối bao gồm ĐTĐTK, dị tật thai nhi, nhiễm trùng thai và 1 số nguyên nhân hiếm gặp khác. Đa ối trong ĐTĐTK thường kèm theo thai to. Nghiên cứu của tác giả Idris và cộng sự cho thấy đa ối (2010) gặp trong 18,8\% trường hợp me bị ĐTĐTK. Điều này là hoàn toàn phù hợp với khuyến cáo của Hiệp hội Sản Phụ khoa Pháp cho rằng cần tiến hành sàng lọc ĐTĐTK cho những thai phụ có biểu hiện thai to và đa ối, bởi đây chính là hậu quả của tình trạng tăng cao nồng độ Glucose máu ở người mẹ. Theo Vũ Thanh Vân (2012), thai to kèm đa ối chủ yếu gặp ở nhóm ĐTĐTK chiếm tỷ lệ 20,67\% ở tuân 29- 31. Những trường hợp đa ối không kèm dị tật cũng là dấu hiệu chỉ định làm sàng lọc ĐTĐTK. Trong nghiên cứu của Farooq và cộng sự cho thấy tỷ lệ đa ối ở các thai phụ ĐTĐTK chiếm tỷ lệ $18 \%$, cao hơn so với các thai phụ không ĐTĐTK [10].

\section{KẾT LUẬN}

Độ tuổi trung bình của bệnh nhân ĐTĐTK là $32,05 \pm 4,89$ tuổi, tuổi nhỏ nhất là 20 tuổi và độ tuổi lớn nhất là 43 tuổi.Phần lớn bênh nhân được phát hiện ĐTĐTK trong khoảng thời gian từ 24 đến 28 tuân, chiếm tỷ lệ 71,76\%.Thai phụ có thừa cân và béo phì có tỷ lệ mắc ĐTĐTK cao (chiếm 35,53\%). Thai phụ ĐTĐTK có tỷ lệ tăng cân $>12 \mathrm{~kg}$ trong quá trình mang thai chiếm cao với tỷ lệ là $31,17 \%$.Tại thời điểm phát hiện ĐTĐTK có 30,59\% bệnh nhân được xác định đa ối.

\section{TÀI LIẸU THAM KHẢO}

1. Alberti KGMM, Zimmet PZ. Definition, diagnosis and classification of diabetes mellitus and its complications. Part 1: diagnosis and classification of diabetes mellitus. Provisional report of a WHO Consultation. Diabetic Medicine. 1998;15(7):539553. doi:10.1002/(sici) 1096 9136(199807)15:7<539::aid-dia668>3.0.co;2-s

2. Hartling $L$, Dryden DM, Guthrie $A$, et al. Screening and Diagnosing Gestational Diabetes Mellitus. Agency for Healthcare Research and Quality (US); 2012.

3. Dornhorst A, Paterson CM, Nicholls JSD, et al. High Prevalence of Gestational Diabetes in Women from Ethnic Minority Groups. Diabetic Medicine. 9(9):820-825. doi:10.1111/j.14645491.1992.tb01900.x

4. Lương Thanh Hương. Nghiên Cứu Sàng Lọc Đái Tháo Đường Thai Kỳ ở Thai Phụ Đến Khám Tại Bênh Viên Trung Ương Thái Nguyên. Luân văn Thạc sĩ Y Học, Trường Đại Học Y Hà Nội.; 2018.

5. Lê Thi Thanh Tâm, Đăng Thi Minh Nguyêt, Nguyền Cảnh Phú. Nhận xét kết quả xét nghiểm sàng lọc bệnh đái tháo đường thai kỳ tại thành phố Vinh, Nghê An. Tap chí Y học thực hành. 2016;997(2/2016):124-126. 
6. Martino J, Sebert S, Segura MT, et al. Maternal Body Weight and Gestational Diabetes Differentially Influence Placental and Pregnancy Outcomes. J Clin Endocrinol Metab. 2016;101(1):59-68. doi:10.1210/jc.2015-2590

7. Torloni MR, Betrán AP, Horta $B L$, et al. Prepregnancy BMI and the risk of gestational diabetes: a systematic review of the literature with meta-analysis. Obes Rev. 2009;10(2):194-203. doi:10.1111/j.1467-789X.2008.00541.x
8. Brunner $S$, Stecher $L$, Ziebarth $S$, et al Excessive gestational weight gain prior to glucose screening and the risk of gestational diabetes: a meta-analysis. Diabetologia. 2015;58(10):22292237. doi:10.1007/s00125-015-3686-5

9. Vũ Thanh Vân. Môt Số Nhân Xét về Bênh Đái Tháo Đường ở Phụ Nữ Có Thải ở Bệnh Viện Phụ Sản Trung Ương Năm 2010- 2011. Luân văn tốt nghiệp Bác sỹ Chuyên khoa 2, Trường Đại Học Y Hầ Nội.; 2012.

\title{
SƯ⿱ TĂNG TRƯỞNG ĐẦU MẶT Ở TRẺ EM NGƯỜI KINH TỪ 7 ĐẾN 9 TUỔI BẰNG PHƯƠ'NG PHÁP ĐO TRÊN ẢNH CHUẨN HÓA THẲNG VÀ NGHIÊNG
}

\author{
Trương Đình Khởi ${ }^{1}$, Lương Ngọc Khuê ${ }^{2}$, Đào Thị Dung ${ }^{3}$,
} Trần Văn Tiến ${ }^{2}$, Hà Ngọc Chiều ${ }^{1}$

\section{TÓM TẮT}

Mục tiêu: Phân tích sự tăng trưởng đâu mặt ở trẻ người Kinh 7 -9 tuổi bằng phương pháp đo trền ảnh chuẩn hóa thẳng và nghiêng. Đối tượng và phương pháp nghiên cứu: Nghiên cứu dọc trên 206 trẻ $7-9$ tuổi người Kinh tại trường Tiểu học Liên Ninh, Thanh trì, Hà Nội bằng phương pháp đo trên ảnh chuẩn hóa thẳng và nghiêng. Kết quá: Các kích thước chiêuu rộng mặt, chiều rộng miệng, chiều rộng hàm dưới, chiều cao tầng mặt trên ở nam lớn hơn ở nữ, không có sự khác biệt có ý nghĩa thống kê giữa ba nhóm khớp cắn theo phân loại Angle, trừ chiều rộng mũi, chiều cao tâng mặt giữa, chiều cao tầng mặt dưới ở loại khớp cắn loại III lớn hơn loại I,II Angle. Các kích thước đầu mặt tăng trưởng diến ra liên tục theo tuổi. Kết luâan: Các kích thước vùng đâu mặt ở nam lớn hơn ở nữ, tẳng trưởng ở nữ có xu hướng sớm hơn ở nam.

Tư khóa: chiều rộng mặt, chiêuu rộng mũi, tăng trưởng đâuu mặt

\section{SUMMARY \\ CRANIOFACIAL GROWTH IN KINH ETHNIC CHILDREN FROM 7 TO 9 YEARS OF AGE IN DIGITAL PHOTOGRAPH - A LONGITUDINAL STUDY}

Objectives: To analysis facial measurements and craniofacial growth in standardized photograph in King ethnic children from 7 to 9 years old. Subjects and methods: A longitudinal study of 206 children (104 males, 102 females) from 7 to 9 years old in Lien Ninh primary school, Thanhtri, Hanoi by measuring in standardized photograph. Results: Average of facial dimensions (facial width, width of mouth, mandibular

${ }^{1}$ Viện Đào tạo Răng Hàm Mặt- Đại học Y Hà Nội 2Cục Khám chữa bệnh và Cục Y tế dự phòng-Bộ y Tế ${ }^{3}$ Khoa Y Dước-Đại học Quốc Gia Hà Nội

Chịu trách nhiệm chính: Trương Đình Khởi

Email: Bskhoirhm@gmail.com

Ngày nhận bài: 5.3.2021

Ngày phản biên khoa hoc: 27.4 .2021

Ngày duyệt bài: 10.5.2021 width, superior height) in male were larger than in female there was not statistical difference among three groups. Conclusion: Most of craniofacial dimensions in male was larger than in female, facial growth in female was significantly sooner than in male.

Keywords: Facial width, nasal width, craniofacial growth

\section{I. ĐĂT VẤN ĐỀ}

Các đặc điểm nhân trắc khuôn mặt là yếu tố quan trọng để nhận dạng của một con người. Các đăc điểm hình thái đâu măt thể hiên rõ nét sư khác biêt trong dân tộc người này so với dân tộc khác. Có nhiều phương pháp đang được sử dụng hiện nay để đánh giá các đặc điểm nhân trắc khuôn mặt, một trong số đó là phương pháp đo đac được tiến hành trên ảnh chụp chuẩn hóa thẳng và nghiêng.

Trên thế giới đã có nhiêu nghiên cứu về hình thái đâu mặt, từ thời kỳ Phục hưng đã có phân loại hình thái khuôn mắt của Leonardo De Vinci (1452-1519), Michelangelo (1475-1564), Albrecht Durer (1471-1528) và Francis Galton (1822-1911) [1]. Nghiên cưu của J.Leon Williams (1920) đưa ra bốn loai hình thái đâu măt bao gôm: mặt tròn, mặt thuôn nhọn, mặt oval và mặt vuông, phân loại này vẫn thường được dùng cho đến ngày nay, nhưng chỉ dựa vào định tính [2]. Nghiên cứu của Celebic.A, Jerolimov.V (2001) chỉ ra phân loại hình thái đâu mặt dựa trên kích thước chiều rộng thái dương, chiểu rộng mă̆t và chiều rộng hàm dưới, đưa ra ba loại hình thái mắt chỉ dựa vào định lượng: Mặt oval, mặt vuông và mặt thuôn nhọn [3].

Tại Việt Nam, đã có một số nghiên cứu về hình thái đầu mặt như nghiên cứu của Lê Đức Lánh (2007) [4], Võ Trương Như Ngọc (2010) [5], Trương Hoàng Lệ Thưy, Nguyển Thị Kim Anh (2012) [6], Trân Tuấn Anh (2016) [7], tuy 